\title{
Are Purkinje Cell Pauses Drivers of Classically Conditioned Blink Responses?
}

\author{
Dan-Anders Jirenhed ${ }^{1} \cdot$ Germund Hesslow $^{1}$
}

Published online: 23 September 2015

(C) Springer Science+Business Media New York 2015

\begin{abstract}
Several lines of evidence show that classical or Pavlovian conditioning of blink responses depends on the cerebellum. Recordings from cerebellar Purkinje cells that control the eyelid and the conditioned blink show that during training with a conditioning protocol, a Purkinje cell develops a pause response to the conditional stimulus. This conditioned cellular response has many of the properties that characterise the overt blink. The present paper argues that the learned Purkinje cell pause response is the memory trace and main driver of the overt conditioned blink and that it explains many well-known behavioural phenomena.
\end{abstract}

Keywords Purkinje cells · Classical conditioning · Cerebellum $\cdot$ Simple spikes $\cdot$ Timing

\section{Classical Conditioning and the Cerebellum}

A widely studied form of motor learning, Pavlovian or classical eyeblink conditioning, is known to depend on the cerebellum [1-3]. In this paradigm, a blink-eliciting unconditional stimulus (US) such as an air puff to the cornea is repeatedly preceded by a neutral conditional stimulus (CS) such as a tone. After a number of paired presentations, the tone will elicit a blink in advance of the air puff [4, 5]. Importantly, this learned conditioned response (CR) is adaptively timed, such that it reaches its maximum amplitude close to the expected onset of the US [5-7].

Dan-Anders Jirenhed

Dan-Anders.Jirenhed@med.lu.se

1 Department of Experimental Medical Science, Lund University, BMC F10, 22184 Lund, Sweden
A large body of evidence has made clear that the most important neural structures involved in this learning are in the cerebellum [1-3]. The hippocampus and forebrain structures seem to be important for trace conditioning where there is a temporal gap of several hundred milliseconds between the offset of the CS and onset of the US [8,9], but for the standard delay conditioning protocol (where CS and US overlap), the cerebellum seems to be sufficient for normal conditioning. Indeed, the similarities between intact and decerebrate cats [10-12] as well as between decorticate and intact rabbits $[13,14]$ or rabbits before and after decerebration [15] are quite impressive.

Work by Yeo et al. indicated that the critical learning site was in the cortical lobule HVI of the cerebellar hemisphere $[16,17]$. Several papers [18-21] in the literature suggest that eyeblink conditioning relies on the cerebellar nuclei and that conditioning is possible without the cerebellar cortex. However, studies of conditioning after cortical inactivation invariably show abnormal CRs with poor or no adaptive timing [22]. We agree with a recent review by Longley and Yeo that the interpretation that makes best sense of the evidence is that the memory trace is located in the cortex [23].

Theories of cerebellar learning proposed by Marr [24] and Albus [25] suggested that the CS might be signalled to the cerebellum via the mossy fibres and the US via climbing fibres (cf. Fig. 1a). This was supported by the demonstration of a convergence in the cerebellar cortex of mossy fibres from pontine nuclei and climbing fibres from the critical part of the inferior olive [26]. These anatomical findings have later been confirmed by extensive physiological and behavioural evidence [1, 2, 27-29].

Albus also suggested that the application of a classical conditioning protocol would lead to the development of an inhibitory response to the CS in a set of Purkinje cells and that this pause in simple spike firing would drive the overt conditioned response. The purpose of the present paper is to review and evaluate the evidence for this suggestion. 


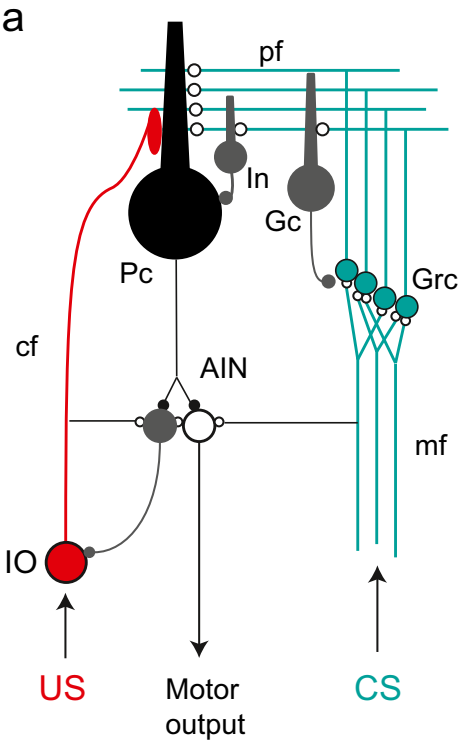

C

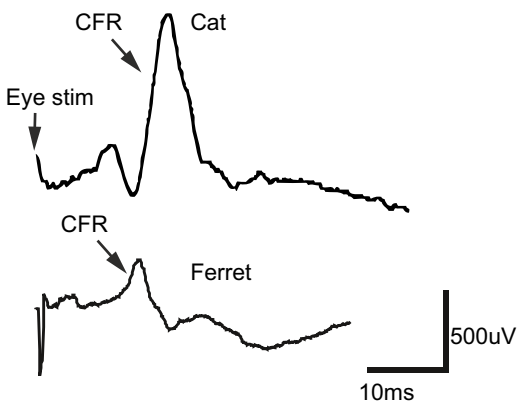

Fig. 1 The cerebellar micro circuit and eyeblink microzones. a Neuronal circuitry in the cerebellum. Excitatory synapses are illustrated with open circles and inhibitory synapses are illustrated with filled circles. Purkinje cells $(P c)$, interneurons (In), Golgi cells $(G c)$, granule cells ( $G r c)$, anterior interpositus nucleus $(A I N)$, inferior olive $(I O)$, mossy fibres $(m f)$, climbing fibres $(c f)$. The conditional stimulus $(C S$, in green) activates mossy fibres $(\mathrm{mf})$ from pre-cerebellar structures like pontine nuclei that transmit signals of different sensory modalities to the cerebellum. The mossy fibres form excitatory synapses onto granule cells $(G r c)$ in the cerebellar cortex and in turn project axons that reach the cerebellar surface and diverge into parallel fibres $(p f)$. The parallel fibres make excitatory synaptic contacts onto Golgi cells $(G c)$, interneurons (Int) and Purkinje cells $(P c)$. The unconditional stimulus $(U S$, in red) activates the inferior olive that projects climbing fibres that converge with the parallel fibres $(p f)$ on the dendrites of the Purkinje cell. Since the Purkinje cell is inhibitory (GABA-ergic), decreased activity in Purkinje cells will cause disinhibition of cells in the anterior interpositus nucleus $(A I N)$ that in turn elicits motor output via downstream motor structures like the red nucleus

\section{Localisation of Blink Controlling Areas in the Cerebellar Cortex}

In evaluating data from Purkinje cell recordings, it is important to identify the precise cerebellar circuits that control the CR. There are two suggestions in the literature for which these circuits might be. Delgado-Garcia and Gruart have proposed that the b

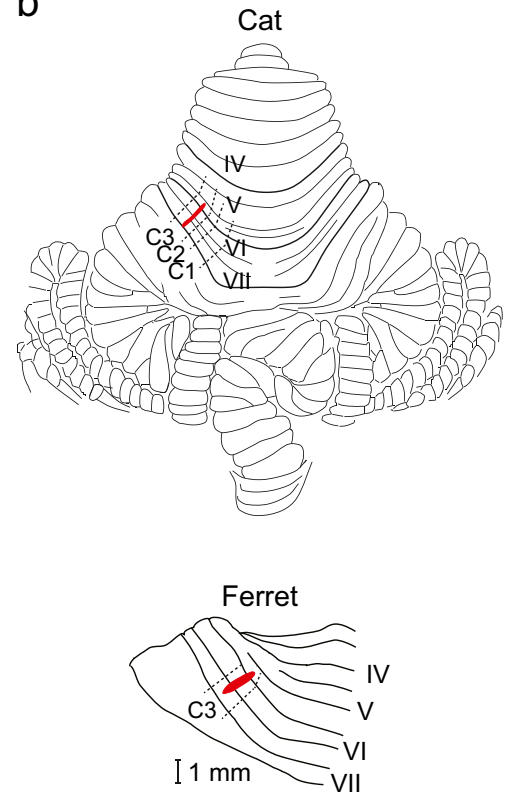

d

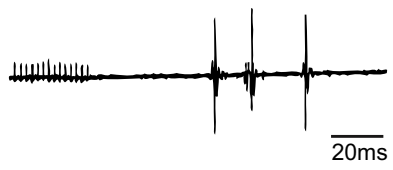

and the facial nucleus in the case of the eyeblink response. A second population of neurons in the anterior interpositus nucleus $(A I N)$ makes inhibitory (GABA-ergic) projections back to the inferior olivary cells that project to the microzone. $\mathbf{b}$ Localization of blink areas in cerebellar cortex in the cat and the ferret. Cerebellar lobules IV-VII are numbered according to Larsell [71]. Approximate borders between the C1, C2 and C3 zones are indicated by dashed lines. Areas in red illustrate the microzones identified in both species that control eyeblink muscles and also receive short-latency climbing fibre input from the periorbital area. Both of these microzones are located in the $\mathrm{C} 3$ zone in the respective species. c Climbing fibre field potential responses $(C F R)$ recorded from the $\mathrm{C} 3$ eyeblink microzone. In the cat (upper trace), the CFR has an onset latency of $14 \mathrm{~ms}$ after stimulation of the periorbital skin. In the ferret (lower trace), the corresponding latency is $11-12 \mathrm{~ms}$. d Delayed eyeblink responses (measured as electromyograms or EMGs) elicited by electrical stimulation of the $\mathrm{C} 3$ eyeblink microzone in the cat cerebellum (red area in panel $\mathbf{b}$ above). Adapted from [38, 49, 63]

CR is modulated by the posterior interpositus nucleus [30]. This nucleus is controlled by the cortical $\mathrm{C} 2$ zone, which receives climbing fibres from the medial accessory olive [31-33]. The authors based their suggestion on the observation that neurons in the posterior interpositus nucleus change their firing rate during both conditioned and unconditioned blinks. Because these changes lag the movements, the authors concluded that the $\mathrm{CR}$ 
had to be initiated elsewhere and that the posterior interpositus neurons and the corresponding Purkinje cells have a modulatory role. Consistent with this, virus tracing showed labelling of rabies virus injected into the eyelid in the posterior interpositus nucleus by Morcuende et al. [34].

An alternative circuit was first suggested by Yeo et al. who found that the critical cerebellar nucleus in rabbits was the anterior interpositus nucleus [35]. This is controlled by the $\mathrm{C} 1$ and $\mathrm{C} 3$ zones (cf. Fig. 1b), which receive their climbing fibres from the rostral dorsal accessory olive [33]. They also showed that lesions of the dorsal, but not the medial, accessory olive abolished CRs [36]. The rabies virus tracing by Morcuende et al. does not necessarily contradict this conclusion, since these authors also found labelling in the anterior interpositus. Additionally, a later study using rabies virus tracing showed labelling restricted to the anterior interpositus nucleus [37].

Electrophysiological work on cats and ferrets in our laboratory has confirmed that microcomplexes involving the $\mathrm{C} 1$ and $\mathrm{C} 3$ zones, the anterior interpositus nucleus and the rostral dorsal accessory olive, are critical for conditioning. Electrical stimulation of the periorbital area elicited climbing fibre responses (cf. Fig. 1c) mainly in lobules VI-VII, consistent with the findings of Yeo et al. [17], including not only $\mathrm{C} 1$ and $\mathrm{C} 3$ but also the $\mathrm{C} 2$ zone. However, electrical stimulation of the cortex could elicit delayed electromyography (EMG) responses in the eyelids only when applied to $\mathrm{C} 1$ or $\mathrm{C} 3$ (cf. Fig. 1d). These responses were probably caused by rebound activation of the nuclear neurons after being inhibited by the overlying Purkinje cells. Stimulation of the $\mathrm{C} 2$ zone, which projects to the posterior interpositus, had no such effect [38]. This demonstrates a signal pathway from the C3 zone via the anterior interpositus to the eyelid. Subsequent work also demonstrated that these Purkinje cells actually controlled the CR. A brief stimulus to the cerebellar cortex in $\mathrm{C} 3$, but not in $\mathrm{C} 2$, during a conditioned blink response caused complete suppression of the response [10].

A reasonable conclusion from this evidence is that Purkinje cells in the $\mathrm{C} 1$ and $\mathrm{C} 3$ zones control the orbicularis oculi muscle and the blink $\mathrm{CR}$ via the anterior interpositus nucleus. Although it involves different motor neurons and muscles, the rabbit nictitating membrane response (elicited by contraction of the retractor bulbi muscle) is also under the control of this cerebellar network [23]. Thus, the evidence does not exclude that the $\mathrm{C} 2$ zone and the posterior interpositus nucleus modulate the CR [30], but it does justify a focus on the $\mathrm{C} 3$ zone when studying Purkinje cells that may be involved in learning and generation of the CR.

\section{Pause Responses in Purkinje Cells During Conditioning}

Because Purkinje cells inhibit the cerebellar nuclei, the view of conditioning proposed by Albus and supported by the evidence summarised above predicts that the Purkinje cells respond to the CS with a suppression or pause in their simple spike firing. That such Purkinje cell pauses can indeed elicit blink responses was recently demonstrated in the intact mouse by Heiney et al. [39] who used optogenetic activation of inhibitory interneurons to transiently silence Purkinje cell simple spike activity.

The first study of Purkinje cell activity in conditioned rabbits was published by Berthier and Moore in 1986 [40]. Steinmetz and collaborators have since reported a series of studies of Purkinje cell responses in intact rabbits, using both single unit [41, 42] and multi unit [43] extracellular recording, as have Halverson and collaborators in a recent study [44]. In addition, there are a number of studies of decerebrate animals: cats [45], guinea pigs [46, 47] and ferrets [48-57]. Most studies have used a tone as the CS, but the work on decerebrate cats and ferrets has used electrical stimulation of the forelimb or mossy fibres (cf. Fig. 2a).

Not all published data support the prediction of a CRrelated pause in firing, and a variety of different response patterns have been reported. In their pioneering study, Berthier and Moore trained rabbits with two CSs, one of which was reinforced and one of which was not. Many Purkinje cells responded differentially to the two CSs, but both increases and decreases in firing in response to the reinforced CS were observed. Also, the studies by Kotani et al. [46, 47] and by Steinmetz et al.[41-43] reported both increases and decreases.

However, when the Purkinje cells were sampled in an area of the $\mathrm{C} 3$ zone that controls the blink $\mathrm{CR}$ and receives reliable climbing fibre input from the US and mossy fibre input from the CS, the results were remarkably uniform. Virtually all Purkinje cells found so far conform to the prediction - after conditioning, they respond to the CS with a suppression, often amounting to a pause, in simple spike firing [48-57] (cf. Fig. 2b).

A plausible explanation for the discrepancies between our findings and those of other groups is that they reflect differences in the sampling of the Purkinje cells. The identification of blink areas that our own findings were based on was not attempted in most other recording studies and may be difficult to do in some species. In cats and ferrets, the blink controlling areas are partly located on the cerebellar surface, but in rabbits, they seem to be buried deep beneath the surface [58] and the technique of stimulating Purkinje cells is difficult to apply. Nevertheless, Green and Steinmetz did attempt this, and although they found Purkinje cells with both increased and decreased firing, the average effect was more similar to our findings, an increase followed by a decrease [42].

Also in agreement with our observations, recent work by Halverson et al. [44] reported that Purkinje cells that received short-latency climbing fibre input from the US and were located in the area identified as controlling the blink CR [58] 


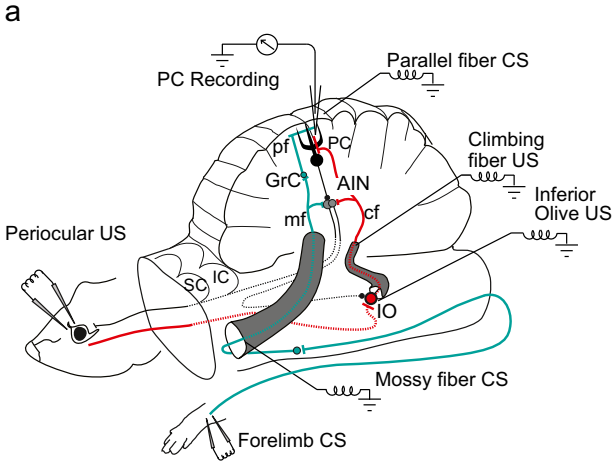

b

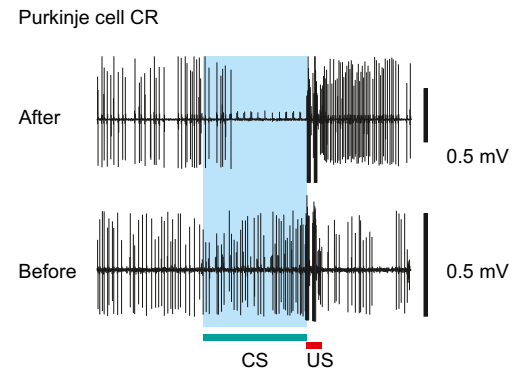

Fig. 2 The decerebrate ferret setup and conditioned Purkinje cell responses. a Experimental setup. After decerebration by transection rostral to the superior (and inferior) colliculi (SC and IC), the remaining structures - brainstem, cerebellum and spinal cord - remain intact and sufficient for classical conditioning of the eyeblink response. This preparation also allows for recording of neural activity in Purkinje cells $(P C)$ in the cerebellar cortex for several hours when the animal is immobilised. As in Fig. 1a, interneurons (In), granule cells $(G r c)$, anterior interpositus nucleus $(A I N)$ and inferior olive $(I O)$. The conditional stimulus $(C S$, in green) was electrical stimulation applied to either the forelimb skin or directly to the mossy fibres $(m f)$ in the middle cerebellar peduncle or to the parallel fibres $(p f)$. The unconditional stimulus $(U S$, in $r e d)$ was electrical stimulation applied to either the periocular skin or directly to the inferior olive $(I O)$ or the climbing fibres $(c f)$ in the inferior cerebellar peduncle. b The conditioned Purkinje cell response (Purkinje cell CR). Simple spike responses recorded extracellularly from a Purkinje cell, before training (bottom) and after $3 \mathrm{~h}$ of training (top), using a mossy fibre conditional stimulus

displayed reliable suppression of simple spikes just before expression of conditioned eyelid responses in the intact rabbit. We conclude that the weight of the evidence supports the working hypothesis that the Purkinje cells controlling the conditioned blink learn to respond to the CS with a suppression of simple spike firing.

It is more difficult to evaluate the role of Purkinje cells that respond to the CS with an increase in activity rather than a decrease, but a plausible speculation is that they are involved in suppressing antagonistic responses, e.g. activation of the levator palpebrae muscle, that would interfere with the blink response. Most behaviours require complex coordination of different muscle responses, and in that context, excitatory Purkinje cell responses in some microzones and pausing in other microzones may be important.

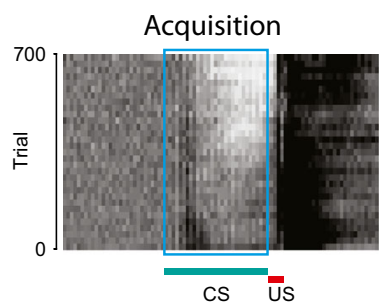

d
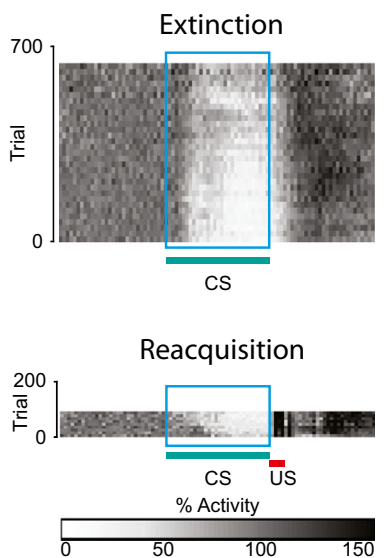

(CS) and a climbing fibre unconditional stimulus (US). Before training, the Purkinje cell responds with a slight increase in simple spike activity. After $3 \mathrm{~h}$ of paired presentations of the conditional stimulus and the unconditional stimulus, the Purkinje cell has acquired a reliable, longlasting pause (for more than $150 \mathrm{~ms}$ ) in response to presentation of the conditional stimulus. The $300-\mathrm{ms}$ interstimulus interval is indicated by the blue shading. c-e Population averages of Purkinje cell simple spike responses to presentations of a conditional stimulus $(C S)$ during (c) acquisition, (d) extinction and e reacquisition. The 300-ms interstimulus interval is indicated by the rectangular box as in (b). Each pixel in the plots illustrates the average simple spike activity for the population of Purkinje cells that was studied, in a 10-ms time window averaged over 20 trials for each cell. The bar below (e) indicates the correspondence between grey scale and simple spike activity, normalised relative to the background simple spike activity in the population. White indicates $0 \%$ simple spike activity and black indicates a $150 \%$ increase in activity compared to background. Adapted from [49, 52]

\section{Conditioning of Purkinje Cell Responses}

\section{Acquisition}

The observation by Berthier and Moore that Purkinje cells responded differently to reinforced and unreinforced CSs suggests that the responses were learned. Even clearer evidence for this comes from studies in which it was possible to record from Purkinje cells for several hours and thus to follow changes in responsiveness to the CS during paired and unpaired CSUS presentations [49]. In intact animals, as well as in decerebrate ferrets, paired stimulation causes acquisition and unpaired stimulation causes extinction of the blink CR. These changes were closely mirrored by the pause responses in Purkinje cells recorded in decerebrate ferrets [49]. When 
recordings were made before conditioning from Purkinje cells in a blink-related area in the $\mathrm{C} 3$ zone, the cells initially either did not respond at all to the CS or responded with a weak excitation (cf. Fig. 2b). During training with paired CS-US presentations every $15-20 \mathrm{~s}$ and an CS-US interval of $300 \mathrm{~ms}$, Purkinje cell CRs usually begin to appear after a couple of hours of training and then gradually grow stronger into a full-blown pause during the next hour. Figure $2 \mathrm{c}$ shows the gradual acquisition of Purkinje cell CRs in the total sample from [49], where clear pause responses begin to appear after about 350 trials. This is quite similar to the acquisition of blink CRs in the same preparation in other studies, where clear blink CRs were observed after at least $2 \mathrm{~h}$ and 350-500 trials of training, although occasionally it could take more than 1,000 trials and $7-8 \mathrm{~h}[59,60]$.

\section{Extinction and Savings}

Unpaired CS-US presentations lead to extinction of blink CRs at a rate comparable to acquisition, and this was also observed with Purkinje cell CRs [49], illustrated in Fig. 2d. Furthermore, behavioural studies have shown that reacquisition of CRs after extinction is very fast. This phenomenon, known as savings, was also reproduced in Purkinje cells, which in some cases could reacquire previously learned and extinguished CRs in less than ten trials [49], illustrated in Fig. 2e. Thus, three of the most fundamental associative characteristics of classical conditioning - gradual acquisition and extinction and rapid reacquisition-were observed in the individual Purkinje cell.

\section{Minimum Interstimulus Interval for Learning}

It has long been known that eyeblink conditioning does not occur if the CS-US interval is shorter than about $80-100 \mathrm{~ms}$ $[61,62]$. This makes physiological sense, because the latency of a normal blink CR is so long and the rise time so slow that the $\mathrm{CR}$ could hardly reach a sufficient amplitude to protect the eye from a US occurring less than $80 \mathrm{~ms}$ after the CS onset [5]. It is also puzzling, however, because the mechanism usually invoked to account for cerebellar learning, long-term depression of parallel fibre to Purkinje cell synapses, would be expected to work just as well for these shorter CS-US intervals [63]. We tested acquisition of Purkinje cell CRs when the CSUS interval was $0,50,100$ and $150 \mathrm{~ms}$. At 0 - and 50-ms intervals, no acquisition of Purkinje cell CRs was observed. Indeed, Purkinje cells instead increased their firing in response to the CS after training with a CS-US interval of $50 \mathrm{~ms}$ (cf. Fig. 3e). With an interval of $150 \mathrm{~ms}$, learning was normal. The graphs in Fig. 3f, showing the relationship between CS-US interval and learning rate in behavioural experiments with rabbits versus the magnitude of Purkinje cell CRs in decerebrate ferrets, are strikingly similar [57].

\section{Temporal Properties of Purkinje Cell CR}

\section{Adaptive Timing}

One of the most distinctive features of conditioned responses is their adaptive timing, i.e. they tend to reach their peak amplitude close to the time of the US $[4,5]$. This means that the time course of the CR is a learned feature of the response and dependent on the CS-US interval [5-7]. Recordings in decerebrate ferrets have shown highly consistent results, where onset latencies to start and peak for Purkinje cell CRs were closely related to the CS-US interval used during training [50] (see Fig. 3a-d). Also, if the CS-US interval is increased and training is continued with the longer interval, then the temporal profile of the response will become adapted to the new longer interval [50].

After learning, the time course of Purkinje cell CRs and blink CRs can vary between different animals, as well as between individual trials in the same animal, but the best timing estimates are consistent with the causal direction being from Purkinje cells to eyelid movements. In studies of blink CRs measured by EMG recordings in decerebrate ferrets, the blink CR onset latencies after CS onset were usually around $100 \mathrm{~ms}$ and the duration was typically 150-200 $\mathrm{ms}[27,59,60,64,65]$ after conditioning with a CS-US interval of $300 \mathrm{~ms}$. In later studies in which Purkinje cells had been trained with the same interval, average onset latencies were $50-120 \mathrm{~ms}$ and durations were $150-200 \mathrm{~ms}$ or longer $[49,50,52]$.

In rabbits, excitatory responses in the interpositus nucleus show lead times of 60-75 ms before the blink and nictitating membrane responses [66-68]. Thus, a $150-200-\mathrm{ms}$ pause in Purkinje cell simple spike activity starting at 50-120 ms after CS onset would provide sufficient time for an excitatory (disinhibitory) nuclear response to elicit a well-timed blink after delays downstream through the red nucleus and facial nucleus. Indeed, Heiney et al. [39] recently demonstrated that optogenetic silencing of Purkinje cell activity in vivo in mice can produce an increase in nuclear cell activity already within $6 \mathrm{~ms}$ and subsequent eyelid movements within $20 \mathrm{~ms}$. Additional data consistent with these estimates was recently provided by Halverson et al. [44], who reported that onset of Purkinje cell CRs in the intact rabbits preceded the onset of blink CRs by approximately $100 \mathrm{~ms}$ when Purkinje cell responses and blink responses were recorded simultaneously.

In our studies using the decerebrate ferret preparation, we wanted to record from Purkinje cells during many hours of conditioning in order to capture changes in Purkinje cell behaviour from the naïve state through phases of acquisition, extinction and reacquisition. We also wanted to be able to directly stimulate mossy fibre and climbing fibre afferents in order to control both the sources of input and the temporal properties of the CS and US to the Purkinje cell. This required immobilisation for tissue stability, which precluded simultaneous recording of behaviour. 
a

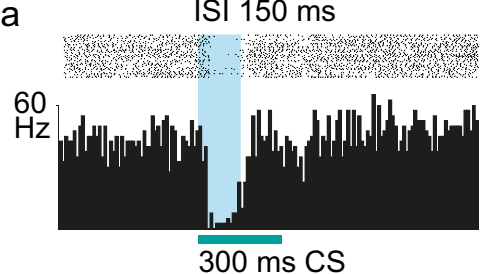

b

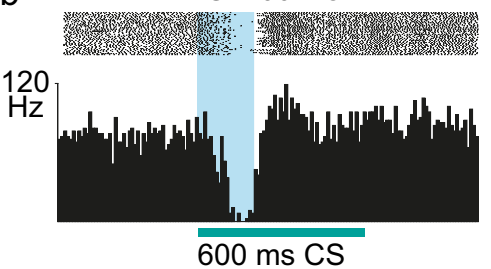

C
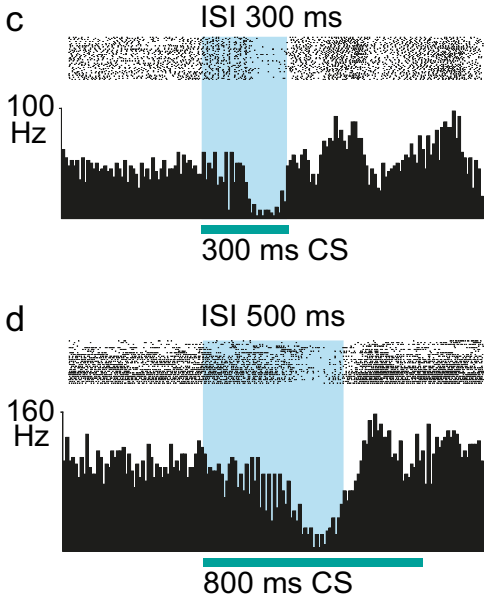

Fig. 3 Adaptive timing of conditioned Purkinje cell responses. One of the most important common characteristics for both the conditioned eyeblink response and the conditioned Purkinje cell response is that the temporal response profile is adaptively timed in accordance with the CS-US interval (or interstimulus interval, $I S I$ ) indicated with blue, between presentation of the conditional stimulus $(C S)$ and the unconditional stimulus (US). Just like conditioned eyeblink responses, conditioned Purkinje cell responses occur just prior to the expected onset of the unconditional stimulus. Panels (a-d) illustrate responses in four Purkinje cells that were conditioned using paired mossy fibre stimulation as the conditional stimulus $(C S)$ and climbing fibre stimulation as the unconditional stimulus, separated by different CS-US intervals (interstimulus intervals, ISIS) indicated in blue-150, 200, 300 and $500 \mathrm{~ms}$. The temporal profiles of the conditioned responses differ with regard to latencies to onset, maximum and offset in accordance with the interstimulus interval used during training. Longer interstimulus intervals compared to shorter caused acquisition of responses that had longer latencies to onset, maximum and offset. For each Purkinje cell, simple spike activity was recorded during 40 presentations of the conditional stimulus alone. The 40 records of $1,500 \mathrm{~ms}$ duration were aligned, with a 500 -ms pre-stimulus period showing the Purkinje cell's baseline simple spike activity, followed by the responses to presentations of the conditional stimulus. In the raster plots above the histograms, each dot represents the occurrence of a simple spike. Each bin in the histograms represents the average instantaneous simple spike frequency in a 10-ms time bin. Conditional stimulus durations varied between 300 and $800 \mathrm{~ms}$ but were always equal to or greater than the e ISI $50 \mathrm{~ms}$

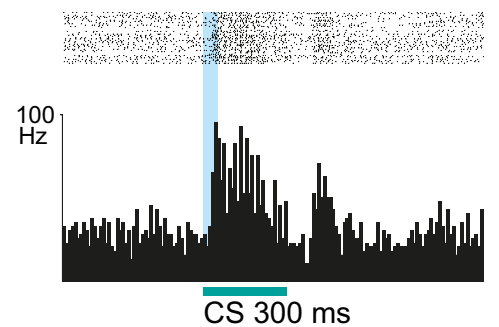

f

\section{Pc response learning compared to rabbit behaviour learning.}

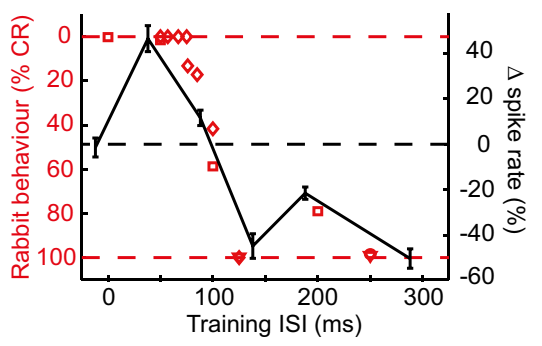

interstimulus interval. e Interstimulus intervals less than $100 \mathrm{~ms}$ are not conducive to conditioning of eyeblink responses. The same is true for the conditioned Purkinje cell response. Responses recorded from a Purkinje cell after conditioning to a 50-ms interstimulus interval between presentation of a 300-ms conditional stimulus, consisting of 31 electrical pulses delivered to the mossy fibres at $50 \mathrm{~Hz}$, paired with electrical stimulation of the climbing fibres as the unconditional stimulus. In contrast to results after conditioning to interstimulus intervals of $150 \mathrm{~ms}$ or more (c-f below), training with a $50-\mathrm{ms}$ interval does not produce a conditioned pause response but instead induces a learned excitatory response to the conditional stimulus. f The effects of CSUS intervals (or interstimulus interval, ISI) on conditioning of the rabbit behaviour (nictitating membrane response) are mirrored by the magnitude of conditioned Purkinje cell responses in ferrets. To compare the interstimulus interval effects on Purkinje cell responses and nictitating membrane responses, we re-plotted rabbit classical conditioning data on a reversed $y$-axis, as well as the mean Purkinje cell simple spike modulation as a function of interstimulus interval. (The curve showing Purkinje cell responses is shifted $5 \mathrm{~ms}$ backward to compensate for the shorter latency of climbing fibre activation that occurs with direct climbing fibre stimulation as the unconditional stimulus.) As can be seen, interstimulus intervals below $100 \mathrm{~ms}$ do not produce conditioning of either the behavioural response in the rabbit or the Purkinje cell pause response in the ferret. In fact, there is a strong match between the behavioural response frequency and the effect on Purkinje cell simple spike activity in response to the conditional stimulus, throughout the spectrum of interstimulus intervals from 0 to $300 \mathrm{~ms}$. Adapted from [50,57] 
We could compare Purkinje cell data during various experimental conditions with behavioural (EMG) data from nonimmobilised animals subjected to the same stimulation protocols, but this precluded trial-by-trial comparisons of comparison of Purkinje cell CRs with overt CRs. In the recent work by Halverson et al. [44], however, this was done and the data show impressive correlations between Purkinje cell and overt CRs at the trial-by-trial level.

\section{Effects of Conditional Stimulus Parameters}

After delay conditioning, the time course of the blink CR depends mainly on the initial part of the CS. Although acquisition of the $\mathrm{CR}$ may require the $\mathrm{CS}$ to be temporally contiguous (i.e. without a trace period between the end of the CS and beginning of the US), post-training presentation of a brief part of the CS (e.g. the first $50 \mathrm{~ms}$ of a 300-ms CS) is sufficient to elicit a blink $\mathrm{CR}$ with a normal temporal profile including the characteristic latencies to onset, peak and offset [59]. This is the case also for the Purkinje cell CRs. When Purkinje cells had been trained using a specific CS-US interval, such as 200 or $300 \mathrm{~ms}$, with a $50-\mathrm{Hz}$ electrical stimulation of the mossy fibres as the CS, Purkinje cell CRs with essentially normal time course could be elicited by very brief CSs, sometimes only a single pulse. In addition, the Purkinje cell CRs always stopped near the expected US onset, even if the CS was continued for several hundred milliseconds after the US [51]. This means that the initial part of the CS-elicited mossy fibre activation provides the necessary and sufficient input to elicit the entire learned response, both at the cellular level and the behavioural level.

Behavioural studies of decerebrate ferrets conditioned to blink in response to electrical stimulation of the forelimb skin or mossy fibres showed that a sudden increase in CS intensity or of the stimulation frequency caused a shortening of latencies to CR onset and maximum [60]. A similar phenomenon was later observed in Purkinje cell CRs where an increase in the intensity of a forelimb electrical CS or the frequency of a mossy fibre CS caused a stronger simple spike suppression with faster onset [56].

The observations summarised so far were all made in experiments where the CS was applied to the forelimb or to the mossy fibres. However, it was recently shown that Purkinje cell CRs can also be acquired when direct parallel fibre stimulation is used as the CS and that the temporal properties of the Purkinje cell CR do not depend on a temporal code in its CS input signal. Instead, the temporal properties of the Purkinje cell $\mathrm{CR}$ are due to intrinsic cellular mechanisms $[52,69]$.

\section{Conclusion: Purkinje Cell CRs Drive the Overt CRs}

The many striking similarities between Purkinje cell CRs and overt blink CRs reviewed above strongly suggest a causal relationship but do not exclude that the Purkinje cell responses are caused by the overt CR or that both are effects of a common cause. However, a number of considerations argue against such interpretations. The most important ones are the following: (1) Purkinje cell CRs are readily learned in immobilised animals excluding the possibility that they reflect peripheral sensory feedback. (2) The fact that Purkinje cell CRs precede the overt CRs excludes that the latter drives the former, although it does not exclude a common cause. (3) Direct electrical stimulation of the cerebellar cortex as well as optogenetic activation of inhibitory interneurons demonstrates that the relevant Purkinje cells control the eyelid. (4) Interference with the Purkinje cells, by electrical stimulation of the cerebellar cortex during the CS-US interval, disrupts the overt CR. (5) The demonstration that timed Purkinje cell CRs can be obtained when the CS is direct stimulation of mossy fibres or parallel fibres where no temporal code is present shows that the temporal properties of the $\mathrm{CR}$ arise within the Purkinje cell.

We think that the evidence summarised here leaves little doubt that the Purkinje cell CR is the main determinant of the overt blink CR and explains much of what is known about the behaviour. In saying this, we do not wish to imply that no sites outside the cerebellar $\mathrm{C} 3$ zone may contribute to the learning. For instance, we know that there are cortical areas beside the one we have studied that control the eyelids $[10,38]$ and these areas, as well as the areas in the $\mathrm{C} 2$ zone, may also contribute to the learning and/or modulation of the CR. As noted above, some authors have also suggested that the cerebellar nuclei are involved in the learning. Whether or not this turns out to be the case, it is clear that a more complete account of the overt blink CR would need to take into account the processing of the Purkinje cell signal through the output pathway and the mechanics of the movement [70].

In order to understand the nature of the memory trace, the Purkinje cell CR, the most promising avenues of research would seem to be a combination of studies in transgenic animals and the development of an in vitro model of classical conditioning.

Acknowledgments This work was supported by grants from the Swedish Research Council to The Linnaeus Centre for Cognition, Communication and Learning at Lund University (349-2007-8695) and to G. Hesslow (09899) and from the Åhlen foundation.

Conflict of Interest The authors declare that they have no competing interests.

\section{References}

1. Hesslow $\mathrm{G}$, Yeo $\mathrm{CH}$. The functional anatomy of skeletal conditioning. In: Moore JW, editor. A neuroscientist's guide to classical conditioning. New York: Springer; 2002. p. 86-146. 
2. Thompson RF, Steinmetz JE. The role of the cerebellum in classical conditioning of discrete behavioral responses. Neuroscience. 2009;162:732-55.

3. McCormick DA, Thompson RF. Cerebellum: essential involvement in the classically conditioned eyelid response. Science. 1984;223(4633):296-9.

4. Gormezano I, Moore JW. Classical conditioning. In: Marx MH, editor. Learning: processes. New York: Macmillan; 1969.

5. Kehoe EJ, Macrae M. Fundamental behavioral methods and findings in classical conditioning. In: Moore JW, editor. A neuroscientist's guide to classical conditioning. New York: Springer; 2002. p. 171-231.

6. Mauk MD, Buonomano DV. The neural basis of temporal processing. Annu Rev Neurosci. 2004;27:307-40.

7. Gallistel C. The organization of learning. Cambridge: Bradford Books/MIT Press; 1990.

8. Moyer Jr JR, Deyo RA, Disterhoft JF. Hippocampectomy disrupts trace eye-blink conditioning in rabbits. Behav Neurosci. 1990;104(2):243-52.

9. Kalmbach BE, Ohyama T, Kreider JC, Riusech F, Mauk MD. Interactions between prefrontal cortex and cerebellum revealed by trace eyelid conditioning. Learn Mem. 2009;16:86-95.

10. Hesslow G. Inhibition of classically conditioned eyeblink responses by stimulation of the cerebellar cortex in the decerebrate cat. $\mathrm{J}$ Physiol Lond. 1994;476(2):245-56.

11. Norman RJ, Buchwald JS, Villablanca JR. Classical conditioning with auditory discrimination of the eye blink in decerebrate cats. Science. 1977;196(4289):551-3.

12. Norman RJ, Villablanca JR, Brown KA, Schwafel JA, Buchwald JS. Classical eyeblink conditioning in the bilaterally hemispherectomized cat. Exp Neurol. 1974;44:363-80.

13. Oakley DA, Russell IS. Neocortical lesions and Pavlovian conditioning. Physiol Behav. 1972;8(5):915-26.

14. Oakley DA, Russell IS. Subcortical storage of Pavlovian conditioning in the rabbit. Physiol Behav. 1977;18(5):931-7.

15. Mauk MD, Thompson RF. Retention of classically conditioned eyelid responses following acute decerebration. Brain Res. 1987;403(1):89-95.

16. Yeo CH, Hardiman MJ. Cerebellar cortex and eyeblink conditioning: a reexamination. Exp Brain Res. 1992;88(3):623-38.

17. Yeo CH, Hardiman MJ, Glickstein M. Classical conditioning of the nictitating membrane response of the rabbit. II. Lesions of the cerebellar cortex. Exp Brain Res. 1985;60(1):99-113.

18. Ohyama T, Nores WL, Medina JF, Riusech FA, Mauk MD. Learning-induced plasticity in deep cerebellar nucleus. J Neurosci. 2006;26(49):12656-63.

19. Mauk MD. Roles of cerebellar cortex and nuclei in motor learning: contradictions or clues? Neuron. 1997;18(3):343-6.

20. Freeman JH, Steinmetz AB. Neural circuitry and plasticity mechanisms underlying delay eyeblink conditioning. Learn Mem. 2011;18(10):666-77.

21. Thompson RF. An essential memory trace found. Behav Neurosci. 2013;127(5):669-75.

22. Attwell PJE, Cooke SF, Yeo CH. Cerebellar function in consolidation of a motor memory. Neuron. 2002;34:1011-20.

23. Longley $\mathrm{M}, \mathrm{Yeo} \mathrm{CH}$. Distribution of neural plasticity in cerebellumdependent motor learning. Prog Brain Res. 2014;210:79-101.

24. Marr D. A theory of cerebellar cortex. J Physiol Lond. 1969;202(2): 437-70.

25. Albus J. A theory of cerebellar function. Math Biosci. 1971;10:2561.

26. Yeo CH, Hardiman MJ, Glickstein M. Classical conditioning of the nictitating membrane response of the rabbit. III. Connections of cerebellar lobule HVI. Exp Brain Res. 1985;60(1):114-26.
27. Hesslow G, Svensson P, Ivarsson M. Learned movements elicited by direct stimulation of cerebellar mossy fiber afferents. Neuron. 1999;24(1):179-85.

28. Mauk MD, Steinmetz JE, Thompson RF. Classical conditioning using stimulation of the inferior olive as the unconditioned stimulus. Proc Natl Acad Sci U S A. 1986;83(14):5349-53.

29. Steinmetz JE, Lavond DG, Thompson RF. Classical conditioning in rabbits using pontine nucleus stimulation as a conditioned stimulus and inferior olive stimulation as an unconditioned stimulus. Synapse. 1989;3(3):225-33.

30. Delgado-Garcia JM, Gruart A. Building new motor responses: eyelid conditioning revisited. Trends Neurosci. 2006;29:330-8.

31. Oscarsson O. Functional organisation of olivary projection to the cerebellar anterior lobe. In: Courville J, de Montigny C, Lamarre Y, editors. The inferior olivary nucleus: anatomy and physiology. New York: Raven; 1980. p. 279-89.

32. Apps R, Garwicz M. Anatomical and physiological foundations of cerebellar information processing. Nat Rev Neurosci. 2005;6:297311.

33. Voogd J, Shinoda Y, Ruigrok TJH, Sugihara I. Cerebellar nuclei and the inferior olivary nuclei: organization and connections. In: Manto $\mathrm{M}$ et al., editors. Handbook of the cerebellum and cerebellar disorders. Dordrecht: Springer; 2013. p. 377-436.

34. Morcuende S, Delgado-Garcia JM, Ugolini G. Neuronal premotor networks involved in eyelid responses: retrograde transneuronal tracing with rabies virus from the orbicularis oculi muscle in the rat. J Neurosci. 2002;22:8808-18.

35. Yeo CH, Hardiman MJ, Glickstein M. Classical conditioning of the nictitating membrane response of the rabbit. I. Lesions of the cerebellar nuclei. Exp Brain Res. 1985;60(1):87-98.

36. Yeo $\mathrm{CH}$, Hardiman MJ, Glickstein M. Classical conditioning of the nictitating membrane response of the rabbit. IV. Lesions of the inferior olive. Exp Brain Res. 1986;63(1):81-92.

37. Gonzalez-Joekes J, Schreurs BG. Anatomical characterization of a rabbit cerebellar eyeblink premotor pathway using pseudorabies and identification of a local modulatory network in anterior interpositus. J Neurosci. 2012;32:12472-87.

38. Hesslow G. Correspondence between climbing fibre input and motor output in eyeblink-related areas in cat cerebellar cortex. J Physiol Lond. 1994;476(2):229-44.

39. Heiney SA, Kim J, Augustine GJ, Medina JF. Precise control of movement kinematics by optogenetic inhibition of Purkinje cell activity. J Neurosci. 2014;34(6):2321-30.

40. Berthier NE, Moore JW. Cerebellar Purkinje cell activity related to the classically conditioned nictitating membrane response. Exp Brain Res. 1986;63(2):341-50.

41. Tracy JA, Steinmetz JE. Purkinje cell responses to pontine stimulation CS during rabbit eyeblink conditioning. Physiol Behav. 1998;65(2):381-6.

42. Green JT, Steinmetz JE. Purkinje cell activity in the cerebellar anterior lobe after rabbit eyeblink conditioning. Learn Mem. 2005;12(3):260-9.

43. Gould TJ, Steinmetz JE. Changes in rabbit cerebellar cortical and interpositus nucleus activity during acquisition, extinction, and backward classical eyelid conditioning. Neurobiol Learn Mem. 1996;65(1):17-34.

44. Halverson HE, Khilkevich A, Mauk MD. Relating cerebellar purkinje cell activity to the timing and amplitude of conditioned eyelid responses. J Neurosci. 2015;35(20):7813-32.

45. Hesslow G. Classical conditioning of eyeblink in decerebrate cats and ferrets. In: Ferrell WR, Proske U, editors. Neural control of movement. New York: Plenum Press; 1995. p. 117-22.

46. Kotani S, Kawahara S, Kirino Y. Purkinje cell activity during classical eyeblink conditioning in decerebrate guinea pigs. Brain Res. 2006;1068(1):70-81. 
47. Kotani S, Kawahara S, Kirino Y. Purkinje cell activity during learning a new timing in classical eyeblink conditioning. Brain Res. 2003;994(2):193-202.

48. Hesslow G, Ivarsson M. Suppression of cerebellar Purkinje cells during conditioned responses in ferrets. Neuroreport. 1994;5(5): 649-52.

49. Jirenhed DA, Bengtsson F, Hesslow G. Acquisition, extinction, and reacquisition of a cerebellar cortical memory trace. J Neurosci. 2007;27(10):2493-502.

50. Jirenhed DA, Hesslow G. Learning stimulus intervals - adaptive timing of conditioned purkinje cell responses. Cerebellum. 2011;10:523-35.

51. Jirenhed DA, Hesslow G. Time course of classically conditioned purkinje cell response is determined by initial part of conditioned stimulus. J Neurosci. 2011;31:9070-4.

52. Johansson F, Jirenhed DA, Rasmussen A, Zucca R, Hesslow G. Memory trace and timing mechanism localized to cerebellar Purkinje cells. Proc Natl Acad Sci. 2014;111:14930-4.

53. Rasmussen A, Jirenhed DA, Hesslow G. Simple and complex spike firing patterns in purkinje cells during classical conditioning. Cerebelllum. 2008;7:563-6.

54. Rasmussen A, Jirenhed DA, Zucca R, Johansson F, Svensson P, Hesslow G. Number of spikes in climbing fibers determines the direction of cerebellar learning. J Neurosci. 2013;33(33):13436-40.

55. Rasmussen A, Jirenhed DA, Wetmore DZ, Hesslow G. Changes in complex spike activity during classical conditioning. Front Neural Circuits. 2014;8:90.

56. Svensson P, Jirenhed DA, Bengtsson F, Hesslow G. Effect of conditioned stimulus parameters on timing of conditioned purkinje cell responses. J Neurophysiol. 2010;103:1329-36.

57. Wetmore DZ, Jirenhed DA, Rasmussen A, Johansson F, Schnitzer MJ, Hesslow G. Bidirectional plasticity of Purkinje cells matches temporal features of learning. J Neurosci. 2014;34(5):1731-7.

58. Mostofi A, Holtzman T, Grout AS, Yeo CH, Edgley SA. Electrophysiological localization of eyeblink-related microzones in rabbit cerebellar cortex. J Neurosci. 2010;30:8920-34.

59. Svensson P, Ivarsson M. Short-lasting conditioned stimulus applied to the middle cerebellar peduncle elicits delayed conditioned eye blink responses in the decerebrate ferret. Eur J Neurosci. 1999;11(12):4333-40.
60. Svensson P, Ivarsson M, Hesslow G. Effect of varying the intensity and train frequency of forelimb and cerebellar mossy fiber conditioned stimuli on the latency of conditioned eye-blink responses in decerebrate ferrets. Learn Mem. 1997;4(1):105-15.

61. Schneiderman N, Gormezano I. Conditioning of the nictitating membrane of the rabbit as a function of the CS-US interval. J Comp Physiol Psych. 1964;57:188-95.

62. Salafia WR, Lambert RW, Host KC, Chiaia NL, Ramirez JJ. Rabbit nictitating membrane conditioning: lower limit of the effective interstimulus interval. Anim Learn Behav. 1980;8:85-91.

63. Hesslow G, Jirenhed DA, Rasmussen A, Johansson F. Classical conditioning of motor responses: what is the learning mechanism? Neural Netw. 2013;47:81-7.

64. Ivarsson M, Svensson P, Hesslow G. Bilateral disruption of conditioned responses after unilateral blockade of cerebellar output in the decerebrate ferret. J Physiol Lond. 1997;502(Pt 1):189-201

65. Ivarsson M, Svensson P. Conditioned eyeblink response consists of two distinct components. J Neurophysiol. 2000;83(2):796-807.

66. McCormick DA, Thompson RF. Neuronal responses of the rabbit cerebellum during acquisition and performance of a classically conditioned nictitating membrane-eyelid response. J Neurosci. 1984;4(11):2811-22.

67. Berthier NE, Moore JW. Activity of deep cerebellar nuclear cells during classical conditioning of nictitating membrane extension in rabbits. Exp Brain Res. 1990;83(1):44-54.

68. Choi JS, Moore JW. Cerebellar neuronal activity expresses the complex topography of conditioned eyeblink responses. Behav Neurosci. 2003;117(6):1211-9.

69. Johansson F, Hesslow G. Theoretical considerations for understanding a Purkinje cell timing mechanism. Commun Integr Biol. 2014;7:6. e994376.

70. Porrill J, Dean P. Recurrent cerebellar loops simplify adaptive control of redundant and nonlinear motor systems. Neural Comput. 2007;19(1):170-93.

71. Larsell O, Jansen J. The comparative anatomy and histology of the cerebellum from Monotremes through Apes. Minneapolis: University of Minnesota Press; 1970. 